\title{
Small-Volume Analysis of Cell-Cell Signaling Molecules in the Brain
}

\author{
Elena V Romanova ${ }^{1}$, Jordan T Aerts ${ }^{1,2}$, Callie A Croushore ${ }^{1}$ and Jonathan V Sweedler, ${ }^{*, 2}$ \\ ${ }^{1}$ Beckman Institute for Advanced Science and Technology and the Department of Chemistry, University of Illinois at \\ Urbana-Champaign, Urbana, IL, USA; ${ }^{2}$ Neuroscience Program, University of Illinois at Urbana-Champaign, Urbana, IL, USA
}

Modern science is characterized by integration and synergy between research fields. Accordingly, as technological advances allow new and more ambitious quests in scientific inquiry, numerous analytical and engineering techniques have become useful tools in biological research. The focus of this review is on cutting edge technologies that aid direct measurement of bioactive compounds in the nervous system to facilitate fundamental research, diagnostics, and drug discovery. We discuss challenges associated with measurement of cell-to-cell signaling molecules in the nervous system, and advocate for a decrease of sample volumes to the nanoliter volume regimen for improved analysis outcomes. We highlight effective approaches for the collection, separation, and detection of such small-volume samples, present strategies for targeted and discovery-oriented research, and describe the required technology advances that will empower future translational science. Neuropsychopharmacology Reviews (2014) 39, 50-64; doi: 10.1038/npp.20I3.145; published online 3 July 2013

Keywords: mass spectrometry; sampling; single-cell analysis; lab-on-chip; CE-MS; neurotransmitters

\section{INTRODUCTION}

Multicellular animals are unbelievably complex and show multidimensional specialization and cooperation at the cellular level. In vertebrates, hundreds of distinct cell types are known (Alberts et al, 1994) and the behavior of each individual cell is carefully regulated to meet the needs of the organism as a whole under specific environmental conditions. Alteration and breakdown in the regulatory pathways affect cell function and ultimately the survival of the entire organism. Understanding the molecular mechanisms of cellto-cell communication has thus become an active research area in both fundamental science and drug discovery.

The nervous system, and the brain in particular, have an astounding capacity to store, process, and route information. Interneuron communication is a foundation for brain function and occurs primarily by chemical mechanisms acting via fast-wired (synaptic) or slow-volume transmission through diffusion in the extracellular fluid of the extracellular space (Agnati et al, 2010). Many different kinds of molecules transmit information between the cells

${ }^{*}$ Correspondence: Professor JV Sweedler, Beckman Institute for Advanced Science and Technology and the Department of Chemistry, University of Illinois at Urbana-Champaign, 600 South Mathews Avenue 63-5, Urbana, IL 61801, USA, Tel: +1 217244 7359, Fax: + 1217265 6290, E-mail: jsweedle@illinois.edu

Received 26 March 2013; revised 26 April 2013; accepted 6 May 2013; accepted article preview online 10 June 2013 in the nervous system. Structurally, the signaling molecules used by animals range in complexity from simple gases and small organic molecules to large peptides (Cooper and Hausman, 2009). Perhaps, the most well-investigated transmitters present within the central nervous system (CNS) are amino acids (Glu, Asp, Gly, Tau, dSer, and GABA) and biogenic amines derived from aromatic amino acids such as serotonin, dopamine, and epinephrine. Closely related and metabolically associated with the wellknown monoamines are trace amines (phenolamines, tyramine, and octopamine), which are found in mammalian brain and peripheral nervous tissues at substantially lower concentrations (Burchett and Hicks, 2006). Lipid messengers such as endocannabinoids are involved in short- and long-term synaptic plasticity throughout the brain (Katona and Freund, 2012; Pineiro and Falasca, 2012). The gases, nitric oxide (NO) and carbon monoxide, have unique physicochemical properties that enable them to diffuse across cell membranes, thus affecting receptors and other targets located hundreds of microns from the release site (Stern and Filosa, 2013). Neuropeptides are the largest and most functionally and structurally diverse class of cell-tocell signaling molecules. Adding complexity, the same transmitters may act via wired and volume transmission (Agnati et al, 2010). The large assortment of chemical messengers and the diversity of their chemical and physical properties require a complex suite of measurement techniques and integrated approaches for dissecting the 
molecular mechanism of cell-to-cell communication in the brain.

Understanding a multifaceted biological process such as chemical signaling often begins with the measurement and identification of essential molecular players. Measuring signaling molecules in the brain continues to be an involved analytical task. One of the complexities stems from the fact that the organizational structure of the brain has an intricate hierarchical configuration, with bidirectional communication taking place between its cellular components. Two major brain cell types, neurons and glia, further classified in at least 10 subtypes by morphology and function, are interconnected into this intricate architecture. In the cerebral cortex alone, there are roughly 125 trillion synapses, and a single synapse may contain 1000 molecular-scale switches (Micheva et al, 2010). A sample of brain tissue as small as a few microliters includes extracellular matrix and infiltrating vasculature and whole blood, in addition to neural cells (Figure 1), with overlapping but different chemical compositions. Equally fascinating as this morphological complexity is the chemical complexity and myriad forms of intercellular communication in the nervous system (Agnati et al, 2010). Neurons and glia have regulated secretory pathways (Stern and Filosa, 2013) where bioactive peptides and low-molecular-weight transmitters coexist in a cell and can even be released together. Cotransmission, however, is plastic and sensitive to environmental stimuli and pathological conditions. Neurons have been shown to store and release different subsets of transmitters at different synapses (Samano et al, 2012). In addition, neurons and glia can release exosomes containing receptor subunits, structural proteins, mitochondrial DNA, and RNA in a process regulated by synaptic activity (Lachenal et al, 2011). Moreover, re-specification of transmitters may occur in vivo in some neurons after synapse formation under environmental factors such as light changes (Dulcis and Spitzer, 2008).

Another challenge in the analysis of signaling is the relatively low effective concentrations of bioactive compounds present in the CNS. This is true for peptides, small transmitters, and gases that elicit their biological effects via volume transmission (Agnati et al, 2010) and act at nanomolar or lower concentrations far from their release sites (van den Pol, 2012). Neuropeptide binding affinity to cloned receptors is nearly $1000 \times$ higher than that of classical transmitters, often acting far from the synaptic cleft. In contrast, classical transmitters can be found at high local concentrations in the synaptic cleft (Barberis et al, 2011), but have short half-lives in the brain's extracellular space (Merighi et al, 2011). These facts suggest that the temporal dynamics and concentration profiles are different among distinct classes of bioactive compounds. The effects of peptide release develop relatively slowly and are long lasting because they are often mediated by G-proteincoupled receptors that are not spatially restricted to the synaptic structure, whereas fast amino acid transmitters operate via ionotropic receptors directly at synaptic sites on the millisecond time scale (van den Pol, 2012).
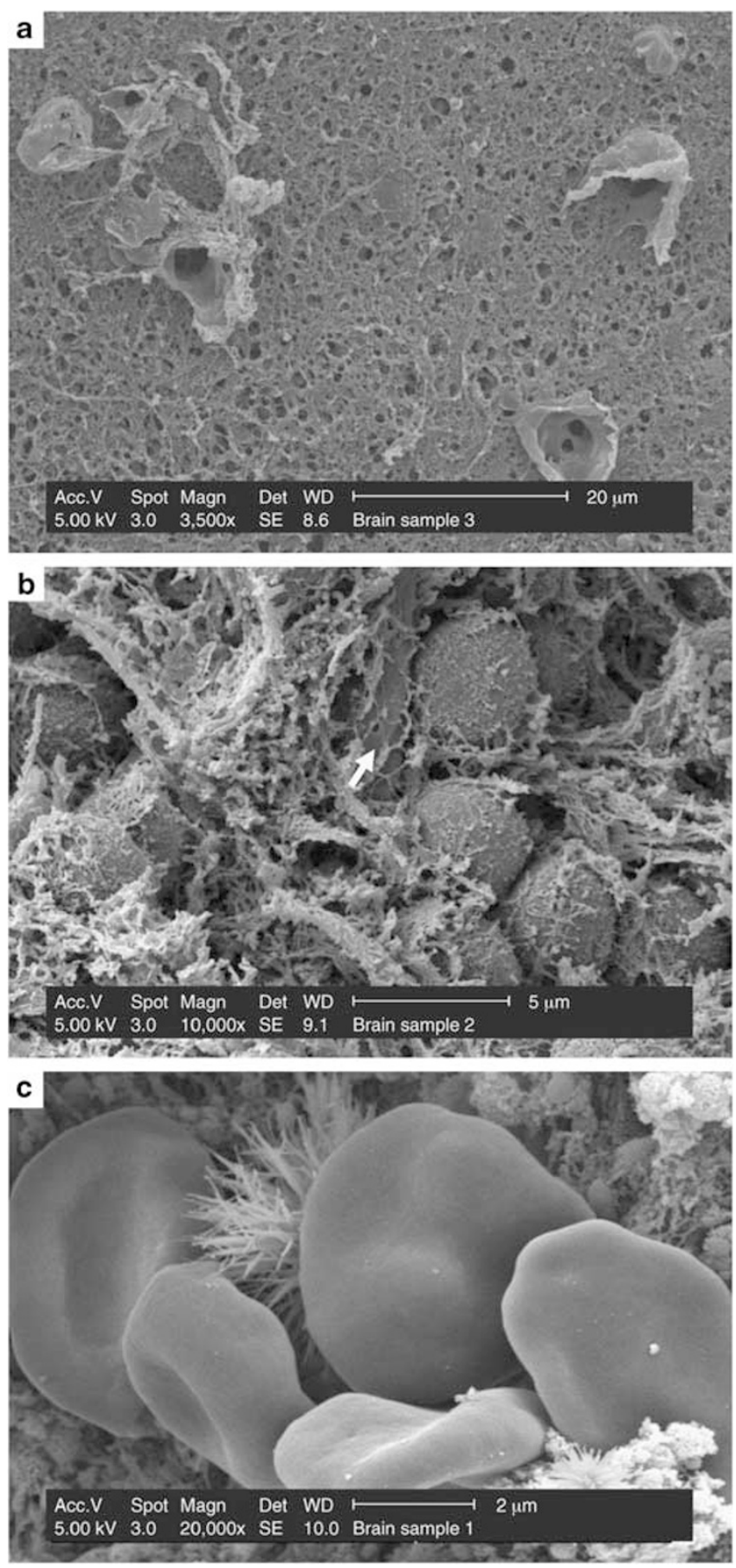

Figure 1. Scanning electron micrograph of rat brain tissue. (a) Torn blood vessels are seen on the surface of a tissue slice and (b) individual cortical neurons are seen among the extracellular matrix. Elongated structure near neurons (arrow) is apparently a vasculature element; (c) erythrocytes seen among salt crystals on the dry fractured surface of a brain slice.

Given this structural and chemical complexity, measuring signaling compounds in the brain with relevance to specific experimental paradigms continues to challenge analytical science. Although most chemically information-rich measurement approaches require large samples representing hundreds of thousands of cells, nanoliter and picoliter 
volume analyses offer many advantages for bioanalytical measurements in the nervous system. Decreasing the tissue sample size to the near cellular scale reduces the structural and chemical heterogeneity of the sample, improves the selectivity of measurement, and offers greater potential to correlate sample chemistry with biological function and pathology.

The tools and techniques that are able to isolate and characterize cellular and subcellular samples from heterogeneous cell populations continue to advance in their capabilities. The tremendous growth in the availability of commercial instruments with ever-increasing sensitivity and performance opens up many new avenues of study. However, the sampling aspects of nanoliter volume analyses still require considerable skill and practice, making them less user-friendly and more difficult to move into a core research facility. At this time, individual cell and other small-volume assays appear better suited to multidisciplinary collaborations between technologists and neuroscience laboratories, with these studies aided by moderate crosstraining by each group.

In the following sections, several approaches that are well suited for characterizing nanoliter-volume samples for their chemical content are described, with particular attention to measurement, quantification, and structural characterization of neurotransmitters, neuromodulators, and metabolites in individual neurons, small populations of neurons, cerebral-spinal fluid, cellular releasates, and brain tissue.

\section{DOWNSIZING WITH SUCCESS}

\section{Sampling Strategies for Microanalysis}

Unlike DNA/RNA-based molecular techniques, bioanalytical measurements of small-volume samples lack a significant signal amplification step. Clever sampling methods, careful sample handling, precise measurement, and sensitive detection are paramount to a successful analysis. Multiple sampling techniques exist for nanoliter volume analysis of peptides and small molecules, as reviewed recently (Cecala and Sweedler, 2012). Not surprisingly, obtaining a pure sample of a tissue region, single-cell, subcellular area, or organelle-with minimal sample dilution and degradation during extraction, cleanup, and analysis-can be difficult. Sampling strategies can be categorized as manual and automated, whereas samples can be classified as solid and liquid.

Manual sample isolation, considered by some as timeconsuming and tedious, is one of the more common approaches and is often unavoidable. For example, sampling of live individual neurons and subcellular neural regions from ganglia, nerves, or other anatomical structures is carried out primarily by hand. In our group, hundreds of samples of individual, live invertebrate, and mammalian nerve cells, and even individual dense core vesicles, have been manually isolated under stereomicroscopic observation from intact ganglia with sharpened tungsten carbide dissection needles (Fuller et al, 1998; Rubakhin et al, 2003, 2006; Romanova et al, 2004, 2007, 2012; Ye et al, 2008). In another approach, individual cells or miniature defined morphological regions have been removed from frozen or fixed tissue sections for neuropeptide analysis (Neupert et al, 2012).

The tools of choice in cell-scale manual sampling are sharpened tungsten needles, super-fine-tip forceps, or small scissors with a micron-scale diameter tip. Glass capillaries can be pulled using pipette pullers to make fine, sharp tips that can be used to cut through soft tissue that might adhere to a cell of interest (Neupert et al, 2012). Alternatively, a pulled glass capillary can be altered by breaking the tip to create a tip diameter slightly larger than the cell of interest, burned to round the edges, and then used to aspirate gently a selected cell for subsequent cleanup and analysis steps while ensuring minimal carryover from surrounding tissue and media. Connecting a glass micropipette to a vacuum line via a length of tubing helps in manipulating the pressure within the capillary for optimal cell capture and transfer. Manual cell isolation can be quite precise (Figure 2), but its success depends on the researcher's fine motor skills. Manual sampling for neurotransmitter measurements in miniature Drosophila brains have been successfully performed from whole freeze-dried flies (Berglund et al, 2013). Freeze-drying dehydrates tissue under reduced pressure by sublimating the water from the tissue directly into the gas phase (Lowry, 1953), thereby preserving tissue structural integrity and morphology.

The manual isolation skills and associated sample manipulations involved in nanoliter volume analyses require significant training to master; once mastered, these tools allow cell-to-cell neurochemical variability to be probed.

Several non-contact isolation methods present more complex but less labor-intensive alternatives. The combination of tapered glass capillary tips with an optical trap have been used to introduce individual intact pinealocytes into a fused silica capillary for the analysis of indolamines and catecholamines by capillary electrophoresis (CE) with laserinduced native fluorescence (Cecala et al, 2012). Laser capture microdissection (LCM) has emerged as a powerful, high-resolution and high-accuracy tool for isolation of specific cell types from tissue sections (Emmert-Buck et al, 1996). More recently, combined with expressed fluorescent tags, LCM has been used to isolate small neurons from Drosophila brain sections (Iyer and Cox, 2010). Popular uses of LCM include DNA, RNA, and proteomics applications (Espina et al, 2006). Isolation of individual live cells from suspensions shows promise for applications of highthroughput single-cell and even organelle microanalysis. A variety of methods, including flow cytometry and microfluidic and array-based platforms, allow cell targeting based on fluorescent tags or even metabolic activity (Nilsson et al, 2009; Suzuki et al, 2009).

Once isolated, a solid biological sample may either be analyzed using techniques such as direct cell/tissue 
a

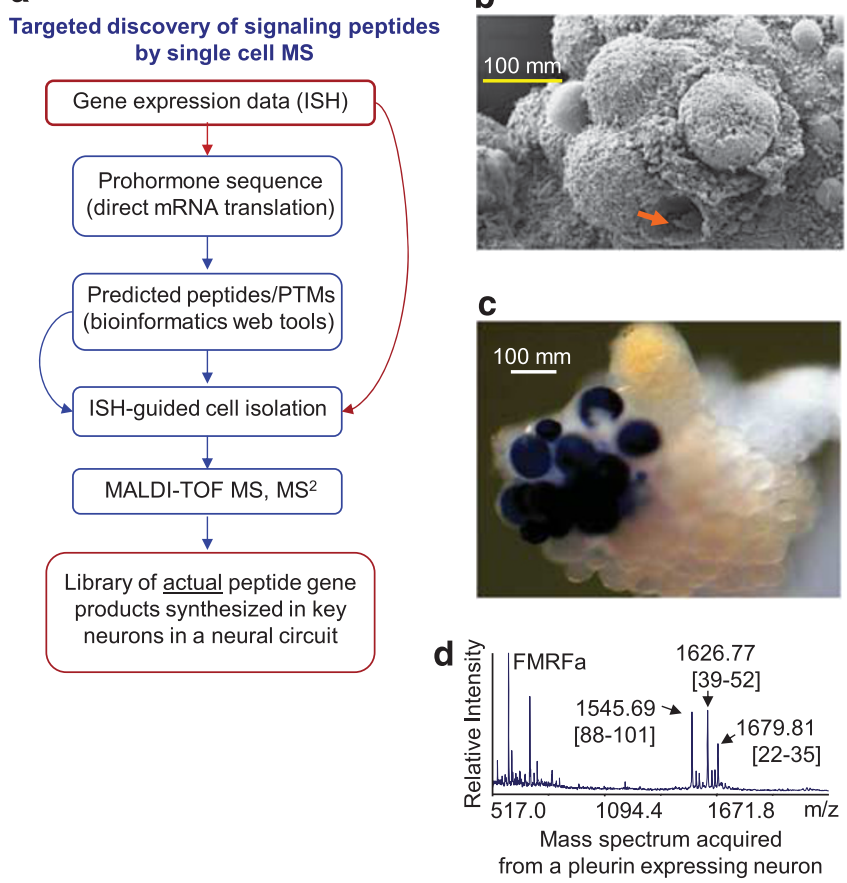

Figure 2. Targeted approach for characterization of neuropeptides. (a) Tried and true workflow for discovery of novel neuropeptides by singlecell mass spectrometry (MS). (b) Scanning electron micrograph of the Aplysia buccal ganglion fixed and imaged after manual isolation of a giant motoneuron for MS analysis. The arrow points to where an isolated neuron was located in a live ganglion before isolation. The image illustrates the precision of manual cell isolation but is not related to the data in (c) and (d). (c) In situ staining showing the localization of pleurin prohormone to a cluster of neurons in the pleural ganglion of Aplysia. The image is courtesy of $L$ Moroz and has been modified from Moroz et al (2006). (d) Actual single-cell mass spectrum obtained on one of the pleurin-expressing neurons shown in (c). Peptides predicted from the pleurin prohormone sequence are labeled by their amino acid positions on the prohormone. FMRF, peptide is also labeled; MALDI-TOF, matrixassisted laser desorption-time-of-flight; ISH, in situ hybridization staining; PTMs, posttranslational modifications.

matrix-assisted laser desorption/ionization (MALDI) mass spectrometry (MS) or analytes can be extracted and measured using a variety of approaches. Individual cells may yield a sample volume of nanoliters, as in the case with large neurons such as human dorsal root ganglion neurons $(\sim 100 \mu \mathrm{m})$ and even larger invertebrate neurons, but typical cells may be $<20 \mu \mathrm{m}$ in diameter and have a volume in the picoliter range. Optimization of analyte extraction from cells or tissue must often be carried out in a compound-specific manner, taking into account analyte stability and solubility in a given extraction solvent. Cold extraction solutions are typically used for small-molecule analysis, as enzymatic activity is generally reduced at lower temperatures, whereas neuropeptides are most often extracted in highly acidic conditions. Temperature and extraction solution additives have been optimized by several groups for mammalian cell metabolomic analyses (Sellick et al, 2009).

Sampling and measuring signaling molecules in vivo at their release sites in an intact brain is an important goal. Microdialysis is one of the most common in vivo sampling techniques for continuous monitoring of drugs and/or endogenous compounds in the extracellular fluid and has been used to study many areas of the brain in different model systems (Sharp and Zetterström, 2006; Behrens and $\mathrm{Li}, 2010$ ). One advantage of this sampling technique is the reduction of protein in the dialysate, which eliminates the concern of neurotransmitter degradation due to enzymatic activity and streamlines the sample cleanup before analysis. Constant replacement of the sampling fluid with fresh perfusate allows coupling of this sampling method to microfluidic devices for further separation and analysis. As changes in the concentration of classical neurotransmitters in the extracellular space occur in milliseconds, several groups have worked to improve temporal and spatial resolution, enabling sampling on release time scales and in much smaller regions than traditional microdialysis. The Kennedy group (Wang et al, 2009) reported an inventive way to reduce dispersion along a sampling channel by introducing a segmented flow system into an online microdialysis setup. By creating discrete aqueous analyte plugs that are surrounded by an oil phase, diffusion broadening is limited to the droplet, and temporal resolution is improved overall. This technique has been used to study both amino acids (Wang et al, 2009) and acetylcholine (Song et al, 2012) from the rat brain. Furthermore, by coupling this segmented flow system to a push-pull perfusion system, Glu was detected with $7 \mathrm{~s}$ temporal resolution and a spatial resolution of $0.016 \mathrm{~mm}^{2}$, an 80-fold improvement over traditional microdialysis (Slaney et al, 2011). The Ismagilov group (Chen et al, 2008) reported a lab-on-a-chip platform, the chemistrode, that consists of a droplet-based delivery system that stimulated single cells and re-formed the released solution into a segmented plug with high spatial resolution $(<15 \mu \mathrm{m})$ and high temporal resolution $(50 \mathrm{~ms})$.

Following sampling, the fractionation/separation of analytes before their characterization often increases the confidence of analyte identification and allows greater numbers of analytes to be characterized from a sample. A particular problem inherent to separations of volumelimited samples is the ability to manipulate small volumes to introduce them into a compatible separation platform without sample losses or excessive dilution. An overview of specialized interfaces for sample introduction into microseparation platforms is presented elsewhere (Cecala and Sweedler, 2012). Microseparations with a range of detection schemes, including fluorescence, electrochemical detection, and MS, allow sensitive and selective analyses of single-cell and other small-volume brain samples.

\section{Microseparation Methods}

Here we outline several separation approaches and highlight the characteristics that define their utility for small-volume neuroscience work. Although conventional liquid chromatography (LC) using a narrow-bore column is well suited for neurochemical analysis and is available in many core 
facilities, its use for nanoliter-volume samples is less routine. The integration of liquid chromatographic separations into microfluidic platforms enhances sensitivity and rapid analysis of volume-limited samples (Rainville, 2011; Lin et al, 2012).

CE separations are easily scaled to sample volumes in the femtoliter to nanoliter volume range, show unsurpassed femtomole to zeptomole mass detection limits with appropriate detection modalities (Ramsay et al, 2009), consume miniscule volumes of buffer, are low cost compared with LC systems, and are more often used as a result (Guihen and O'Connor, 2010). Another benefit of CE, especially for neurochemical applications, is that separation is based on the differential migration of charged molecules; many of the neurotransmitters and neuromodulators in the nervous system are charged over a range of $\mathrm{pH}$ values, and thus can be separated from the cellular milieu under typical $\mathrm{CE}$ conditions. CE has been successfully used for discovering new serotonin metabolites (Squires et al, 2006), and characterizing the content of single cells (Nemes et al, 2012) and single vesicles (Omiatek et al, 2009). Chiral analysis of excitatory acids from the brain by $\mathrm{CE}$ has been reported (Wang et al, 2011; Wagner et al, 2012). In addition, $\mathrm{CE}$ has a potential for high-throughput analysis, and separation times as fast as $20 \mathrm{~s}$ have been reported for catecholamines, as well as a fourfold increase in sensitivity by using short separation capillaries with small inner diameters (Grundmann and Matysik, 2011). A sampling approach that further enhances the concentration sensitivity of CE separations is single-drop microextraction; analyte enrichment ranging from $\sim 7000$-fold for chiral amino acids and up to $\sim 30000$-fold for fluorescent dyes has been reported (Alothman et al, 2012). CE is equally suitable for separation of neuropeptides that are zwitterions and whose overall charge is a function of the $\mathrm{pH}$ of its surroundings. Capillary isoelectric focusing can separate peptides based on their isoelectric points, and has been used for the characterization of crustacean neuropeptides (Zhang et al, 2012) and human cerebrospinal fluid (Ye et al, 2011).

The analysis of nonpolar compounds is possible through the use of a CE variant, micellar electrokinetic chromatography (MEKC). MEKC is a variation of electrophoresis that is optimized for the separation of electrically neutral analytes by the addition of an ionic micelle to the running buffer, with the effect similar to that of a stationary phase in an LC separation. MEKC has been commonly used for fast, high-efficiency separation of amino acid transmitters in microdialysis samples, as reviewed in detail elsewhere (Viglio et al, 2012).

Nanoliter and picoliter volumes permit separation of biological samples in microfluidic devices that are characterized by faster and oftentimes massively parallel performance. Implemented on miniaturized platforms that function according to the scaling rules (Livak-Dahl et al, 2011), microfluidic separations benefit from highly controlled transport of particles suspended in the fluids. The turbulence-free nature of microscale flow allows for the segregation of sample components and the formation of sharp gradients, which is highly useful for investigating concentration-dependent biological phenomena such as cell signaling (Mellors et al, 2013). As one example, microchip electrophoresis has recently been used to monitor neurotransmitter concentrations and blood-brain barrier permeability (Nandi et al, 2010).

\section{Detection Platforms Compatible with Microanalysis}

There are multiple sensitive detection methods that are suitable for nanoliter volume analysis. These include electrochemical, fluorescence, and mass spectrometric detection, which have been reviewed by Trouillon and co-workers, 2013). Electrochemical detection allows for the real-time, sensitive and quantitative analysis of biomolecules. Suitable for miniaturization and microfabrication, this method is very adaptable for measurements in small volumes, but is limited to electroactive compounds. Electrochemical methods for neurotransmitter detection include amperometry and voltammetry, which vary in sensitivity, and in chemical and temporal resolution. Electrochemical detection has been successfully implemented in analyses of nanomolar concentrations of biogenic amines from volume-limited samples such as individual fruit fly heads (Powell et al, 2005; Berglund et al, 2013), fly brain regions (Kuklinski et al, 2010), and individual fly larva brains (Fang et al, 2011).

CE has traditionally been used with fluorescence detection. In one example, a combination of $\mathrm{CE}$ with two-color fluorescence allowed the investigation of glycolipid catabolism in primary rat cerebella neurons with $500 \mathrm{ymol}$ to $1 \mathrm{zmol}$ sensitivity (Essaka et al, 2012). Laser-induced fluorescence (LIF) is the most sensitive detection technique used with CE (Pentoney and Sweedler, 1997); it can not only detect but quantify neurotransmitters in minute volumes of sample based on their retention time and area under the peak curve, and can be used to confirm analyte identity by spectral characteristics relative to known standards (Wise and Shear, 2006; Hatcher et al, 2008; Fossat et al, 2012). A dynamic range of nine orders of magnitude and $120 \mathrm{ymol}$ sensitivity have been reported for glycosphingolipid metabolites (Dada et al, 2011). Applications of this approach to the analysis of single cells and small-volume biological samples have been reviewed elsewhere (Szoko and Tabi, 2010; Lin et al, 2011), with several examples highlighted in the following sections of this article.

MS permits the label-free identification of almost any analyte, can provide structural information for unknown analytes, and thus presents a detection method with the highest possible information content. MALDI MS and nanoelectrospray ionization (nanoESI) MS perhaps are the most suitable for microanalysis. In MALDI (Hillenkamp and Peter-Katalinic, 2007), analyte molecules are typically incorporated into organic matrix crystals that absorb light. The sample is then irradiated with a pulsed laser, causing 
the vaporization and ionization process. The ionized molecules of interest are then measured using an appropriate mass analyzer, oftentimes, a time-of-flight system. With its salt tolerance, attomole sensitivity, minimal sample consumption, and ease of sample preparation, MALDI MS, has been successfully applied to a wide range of analytes, including lipids, oligosaccharides, nucleic acids, peptides, proteins, and other polymers. It has become an excellent approach for qualitative profiling of larger molecular weight signaling molecules such as neuropeptides (Li and Sweedler, 2008; Chen and Li, 2010). MALDI MS can be used for direct analysis of volume and mass-limited biological samples, in solid or liquid states and without purification, but occasionally the approach is paired with a separation platform off-line. High-throughput analyses of single cells deposited from suspension and picoliter-volume aliquots have been demonstrated using high-density microarrays for MS. This approach can anchor samples on $100 \mu \mathrm{m}$ spots, which is equal to 250 sample recipients per $\mathrm{cm}^{2}$, or 250 -fold higher sample density than what is currently available from commercial sample plates for MALDI MS (Urban et al, 2010). Applications of MALDI MS to small-volume analyses of signaling molecules are discussed in the next section.

ESI is an effective detection method for CE separations because charged molecules eluting from the CE capillary can be ionized and introduced into the mass analyzer via ESI conditions. CE-MS (see Figure 3a) is widely used to measure and identify bioactive peptides (Ye et al, 2011), metabolites (Nemes et al, 2011, 2012; Nautiyal et al, 2012; Gholipour et al, 2013), classical neurotransmitters (Lapainis et al, 2009), and amino acids (Moini, 2013). Alternatively, microdialysis sampling can be directly coupled to ESI-MS via nanodroplet segmented flow for in vivo chemical monitoring of neurotransmitters, metabolites, and drugs in the live brain (Song et al, 2012). As another hyphenation solution, CE separations have been integrated into microfluidic devices that also serve as electrospray emitters, although sample loading for small-volume analysis remains a barrier to high-throughput analysis (Mellors et al, 2008; Sun et al, 2010; Lin et al, 2012). A combination of ESI-MS and LIF detection with CE is utilized for many smallmolecule applications, including chiral amino acid analysis (Simó et al, 2010). MS confirmation of analytes detected using LIF is important; however, transferring a particular separation method from a CE-LIF instrument to one with MS detection is challenging because of LIF buffer incompatibilities with MS detection. Recent CE-MS work has shown that separations using smaller inner diameter capillaries (eg, $5 \mu \mathrm{m}$ ) were shown to be less affected by buffer composition (Grundmann and Matysik, 2011).

\section{Quantification Approaches for Small-Volume Samples}

Concentrations of signaling molecules in cells and the extracellular space are dynamic and defined by the balance between synthesis, release, reuptake, and degradation.
Measurement methods that generate concentration- or mass-dependent responses may yield quantitative information based on comparisons of signal intensity between sample cohorts. When known compounds are involved, absolute quantitation is possible by using standards and appropriate calibration curves. Here, we outline several approaches that have worked well for assessing concentration changes in the smallest samples of brain tissues. The combination of CE-LIF, radioisotope labeling and radionuclide detection has been successfully applied to demonstrate synthesis, accumulation, and release of D-aspartate in neurons (Scanlan et al, 2010). The quantitation of biogenic amines has been performed by MEKC with electrochemical detection (Berglund et al, 2013). When quantitation of multiple or unknown bioactive compounds is desired, MSbased quantitation methods are effective because they do not require prior knowledge of sample composition. MALDI MS, in particular, is a flexible platform for measuring small samples, including those that are solid (eg, tissue and cells) or liquid (eg, extracts). In combination with stable isotopic labeling, this method has been used for both relative and absolute quantitation of peptides in single neurons and central nerves (Rubakhin and Sweedler, 2008).

\section{Database Resources for Identification of Unknowns}

The advantage of using microseparation methods combined with MS is the ability to identify the unknown and oftentimes unexpected components of the samples, either via accurate mass or a combination of mass and molecular fragmentation patterns. Most mass spectrometer manufacturers provide software to handle data analysis and compound library searching of both in-house libraries as well as external mass spectrometric public libraries. Several issues complicating the use of the freely accessible chemical databases include error propagation due to redeposition of spectral libraries between databases and erroneous stereochemical and covalent bond descriptors found when chemical identifiers such as InChI and SMILES are interconverted between structures and names (Williams et al, 2012).

Mass spectral databases such as the Human Metabolome Database (HMDB) (http://www.hmdb.ca/) (Wishart et al, 2009) and METLIN offer straightforward search options with $\sim 8000$ and $\sim 25000$ compounds, respectively. Mass spectra for known compounds can also obtained through a search of common name, CAS, SMILES, or InChI. More advanced search parameters, such as structure-based searches capable of searching uploaded or MOL, SDF, CDX structure files or image files, can be used at the publicly accessible database websites such as ChemSpider (http://www.chemspider.com/) and Chemical Entities of Biological Interest (http://www.ebi.ac.uk/chebi/) (Hastings et al, 2013). In addition, METLIN offers a data analysis tool for LC-MS data sets called XCMS online. Users can upload data and after a few simple mouse clicks, be presented with 


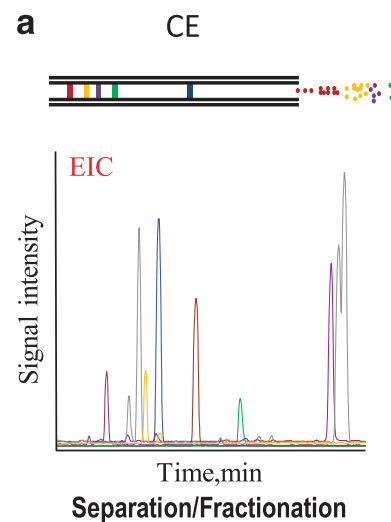

b

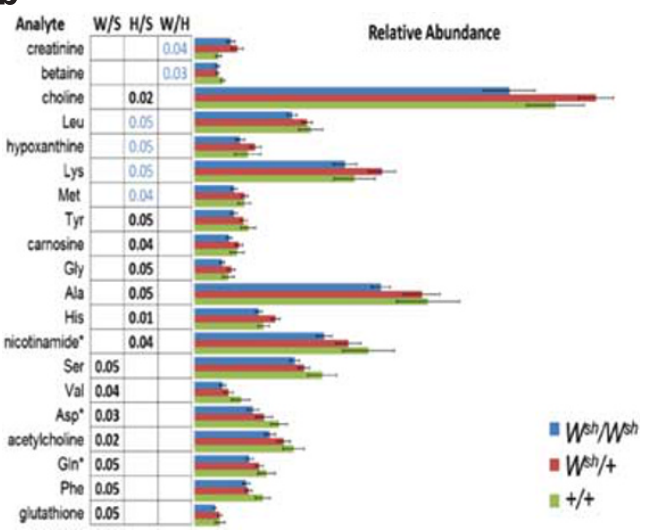

MS/MS

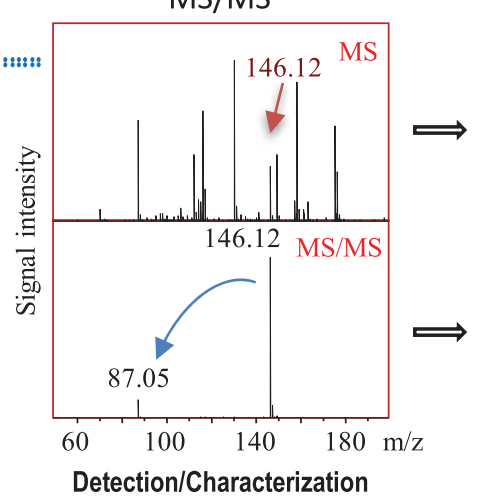

Bioinformatics
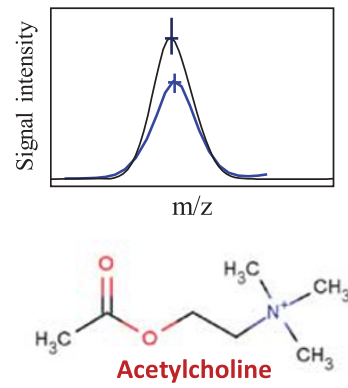

Quantitation \& Identification

C

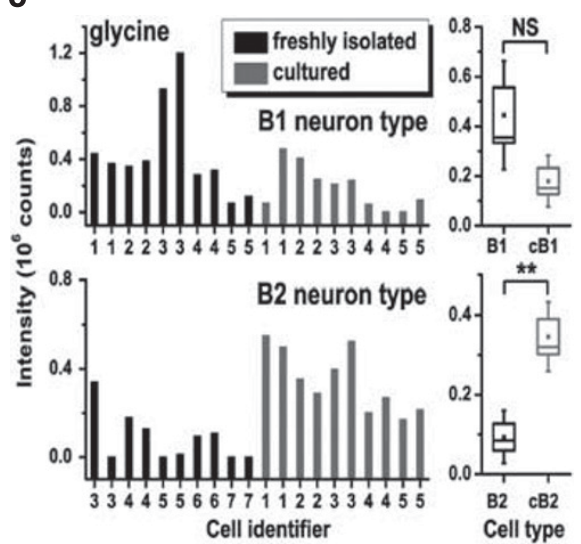

Figure 3. Small-volume metabolomics provides unmatched molecular information on the chemical content of nanoliter-volume samples. Here, a capillary electrophoresis-mass spectrometry (CE-MS) platform is used for qualitative and quantitative characterization of cell-to-cell signaling molecules. (a) Overview of a CE-MS analysis. CE fractionates complex biological samples, which are then introduced to the mass spectrometer via electrospray ionization. Following the measurement of the mass-to-charge ratio of each detectable compound, selected ions are fragmented, and the mass-to-charge of the fragments determined, oftentimes permitting the determination of primary ion structure de novo. Querying the MS data against appropriate chemical and mass spectral databases with the help of bioinformatics tools leads to the identification of analytes and chemical characterization of the sample. EIC, extracted ion electropherogram; $\mathrm{m} / \mathrm{z}$, mass-to-charge ratio; MS, mass spectrometry; MS/MS, tandem mass spectrometry. (b) Statistical results of the CE-MS metabolomics data from individual hippocampi from wild type $+/+(\mathrm{W})$ and mast cell-deficient $W^{\text {sh }} / W^{\text {sh }}(\mathrm{S}), W^{\text {sh }} /+(H)$ mice. Even though there are only about 500 mast cells per mouse brain on average, their lack is correlated to profound neurochemical changes; a total of 20 distinct analytes consisting of amino acids, classical neurotransmitters, and nucleosides exhibit statistically significant differences in relative abundance among tested genotypes. Bars show the mean of normalized abundances measured in the biological replicates for each genotype; error bars represent standard error; $p$-values from the corresponding Student's $t$-tests are tabulated to the left. Statistically significant differences in the levels of these analytes $(p \leq 0.05)$ are also supported by gene expression data. Metabolites associated with differentially expressed metabolic pathways identified by gene expression analysis are marked with black bold in the table. An asterisk indicates that the intensity is reflective of the second peak in the isotopic series due to its high concentration. WT $(\mathrm{W}), W^{\text {sh }} /+(\mathrm{H}), W^{\text {sh }} / W^{\text {sh }}(\mathrm{S})$. (Adapted with permission from Knolhoff et al (2013); Copyright 2013 American Chemical Society.) (c) Statistical analysis of the CE-MS metabolomics data from identified individual Aplysia neurons. The data show cell identity-dependent variations in the neuron chemistry under culture conditions. As one example, an inhibitory neurotransmitter glycine is accumulated in the B2 neurons only. Bars correspond to individual cells measured in technical duplicates. Square, box, and whisker represent statistical median, standard error, and confidence interval, respectively. NS labels statistically insignificant variations, and asterisk $\left(^{*}\right)$ and two asterisks $\left(^{(*}\right)$ mark $p$-values below 0.05 and 0.005, respectively. (Adapted with permission from Nemes et al (2012); Copyright 2012 American Chemical Society.)

results showing statistics, chromatograms, and putative METLIN identities. A recent tool, MetaboSearch (http:// omics.georgetown.edu/MetaboSearch.html) (Zhou et al, 2012), aids in MS-based metabolite identification through the searching of multiple MS databases (HMDB, Madison Metabolomics Consortium Database (http://mmcd.nmrfam. wisc.edu/) (Cui et al, 2008), METLIN, and LIPID MAPS (http://www.lipidmaps.org/) (Fahy et al, 2007)) simultaneously. Mass spectral databases typically link out to each other, as well as to KEGG (http://www.genome.jp/kegg/)
(Kanehisa et al, 2012), PubChem (http://www.ncbi.nlm. nih.gov/pccompound) (Bolton et al, 2008), and others, with additional resources regarding a particular compound of interest. One exciting new website, Chemicalize.org (http:// www.chemicalize.org/), offers an easy-to-use interface that provides most physical properties of a molecule and helps in deciding which approach to take for optimizing a separation.

The aforementioned methods for sampling, separation, measurement, detection, identification, and quantification 
of biologically active compounds in femtoliter to nanoliter sample volumes are readily applicable for studying the CNS in animal models of brain disorders, and potentially also in human subjects. The following section describes specific applications that benefit the most from these small-volume workflows, and highlights less explored but promising approaches.

\section{TECHNOLOGY ROADMAP TO CELL-CELL SIGNALING}

Scaling sample volumes to the level of the cell opens a number of new opportunities for probing brain chemistry. The chemical complement of individual members of defined cell populations can be inventoried, compared, and qualitatively assessed to reveal biomarkers of physiological or developmental states. Disparate elements of neuronal circuits underlying complex behaviors or physiological processes can be characterized to find those elements that show the greatest change, even for surprisingly subtle behavioral perturbations. Dynamic biochemical alterations relevant to a disease state can be monitored. The literature reviewed below demonstrates that these areas are being explored in a range of animal models by small-volume analysis approaches.

\section{Power of One: Single-Cell Analysis for Circuit and Pathway Characterization}

The heterogeneity of a cellular population can result from stochastic gene expression, the deterministic nature of biochemical events occurring in each cell making up the population, and for cells such as neurons with a complex topology, their physicochemical environment, and cell connectivity. Because of the increased ability to study individual cells, a clearer understanding of the effects of the cellular surroundings has emerged, with the awareness that the cellular microenvironment contributes more to cell-tocell variability than stochastic mechanisms can account for (Swain et al, 2002; Stockholm et al, 2007; Raj and van Oudenaarden, 2008; Snijder and Pelkmans, 2011). Of course, neurons within a network that have thousands of connections to other neurons are unique, especially as cells with distinct connections will then respond differently to activity.

Pioneered as a method for investigating electrical connectivity in the neurons, single-cell analysis acquired new dimensions with the advent of bioanalytical MS, as it offers unparalleled chemical information content. One of the more successful MS platforms for chemical profiling of single nerve cells in the circuit or pathway context is MALDI MS. Targeted analysis of neuropeptides in single cells or subcellular regions (Figure 2) greatly benefits from prior genomic information because limited sample amounts often are not sufficient for de novo structural characterization (Romanova et al, 2009). By knowing which genes are expressed in a cell of interest, a library of peptides encoded by the prohormones can be compiled and used as a reference for interpretation of spectra by peptide mass fingerprinting. Groundbreaking research, as reviewed by $\mathrm{Li}$ et al (2000), demonstrated that neuronal circuits can be studied by MALDI MS at the single-cell level, and their chemical content correlated to animal behavior and to specific physiological states. Combined with molecular biology and electrophysiology, single-cell MS is effective for examining neuronal architecture, and for delineating neuronal circuits that regulate physiology and control of instinctive and learned behaviors (Jarecki et al, 2010; Jing et al, 2010; Vilim et al, 2010). Investigations of signaling peptides and their involvement in neural plasticity, learning, memory, complex behavior, and various physiological functions at the level of the individual cell have been successful in invertebrate models (Jimenez et al, 1994; Christie et al, 2010; Li and Smit, 2010; Neupert and Predel, 2010; Neupert et al, 2012). Given the simplicity of their nervous systems and the accessibility of identifiable neurons, invertebrates provide unsurpassed single-neuron resolution and coupling to molecular mechanisms. Currently, single-cell MS is widely being used to characterize novel prohormones (Romanova et al, 2012) and differential prohormone expression (Romanova et al, 2007), map the cellular localization of peptide transmitters (Jimenez et al, 2006; Neupert et al, 2007, 2012; Yew et al, 2009), and analyze neuropeptide release at identified release areas (Fan et al, 2011).

Low-molecular-weight transmitters are also actively measured in defined neuronal networks mediating complex behavior, often with fluorescence detection. Using CE-LIF, the Gillette group (Hatcher et al, 2008) quantitatively measured how 5-HT and related indole metabolites fluctuate with hunger state in well-characterized serotonergic neurons of the feeding motor network of the predatory sea-slug Pleurobranchaea californica. Silver and collaborators (Nautiyal et al, 2012) found that a significant contribution of serotonin to the hippocampal milieu is associated with mast cell activation, which contributes to behavioral and physiological functions of the hippocampus, and later compared the transcriptome and the CE-MS defined metabolome of hippocampi from normal and mast cell-deficient mice (see Figure $3 \mathrm{~b}$ ) (Knolhoff et al, 2013).

Although neuropeptide transmitters and neuromodulators can be characterized in well-defined neuronal circuits, gaseous transmitters such as NO are typically measured using indirect approaches. Various fluorescent NO indicators (Ye et al, 2010), electrochemical sensors (Arafah et al, 2013), or reporters of NO synthase activity (Ye et al, 2008; Potgieter et al, 2010) have been used to track NO in defined neuronal populations and regulatory pathways. The analytical techniques enabling NO detection at single-cell levels include fluorescence microscopy, CE with LIF detection, and electrochemistry ( $\mathrm{Ye}$ et $\mathrm{al}$, 2008). Using fluorescence confocal microscopy, CE, MS, and pharmacological tools, we verified the NO production in specific identified $A$. californica neurons (Ye et al, 2010). NO-selective amperometry has been used for dynamic measurements of NO in 
injured leeches, demonstrating that NO production is regulated through the endocannabinoid system (Arafah et al, 2013).

\section{Freedom of Exploration: Untargeted Analysis of Physiologically Important Compounds on a Small Scale}

While targeted analysis of bioactive compounds is initiated by a biologically rationalized hypothesis, untargeted analysis is often driven by technological development. Highthroughput platforms that comprehensively interrogate the genome, transcriptome, proteome, peptidome, and even secretome in entire organisms or select tissues are certainly desirable in discovery-oriented studies. An important advantage of such approaches is that a priori information on the identity of the compound(s) to measure is not required, and one can measure changes in entire classes of compounds such as RNA, DNA, proteins, and metabolites. Untargeted analyses have the potential to uncover neverbefore-documented chemical relationships that may lead to novel pharmacological targets.

High-throughput, 'omics protocols are not easily adapted for small samples, in part, because the limited amount of material available is not sufficient to achieve systematic analysis of unknowns. Nevertheless, information-rich detection techniques, often powered by MS, push the boundaries of analytical possibilities and initiate new, biologically relevant inquiries. In a study combining $\mathrm{CE}$ separation, MS identification, and chemometric quantification, we investigated cellular heterogeneity among physiologically well-characterized identified neurons of $A$. californica. Out of 300 detected species, 144 were structurally identified, and 50 quantified, revealing surprising differences, not only between neuronal types but also among individual neurons of the same type (Nemes et al, 2011). These observations contribute new evidence about the physiological differences in neuron phenotypes. In a follow-up study, we explored how culturing conditions affect the metabolic profile of individual neurons and found statistically significant changes in the levels of amino acids and small transmitters linked to cell culture conditions (see Figure 3c) (Nemes et al, 2012). With proper experimental design, small-volume exploratory measurements of biological samples may lead to the discovery of biomarkers for disease states. Using CE-MS, Ibanez et al (2012) undertook a non-targeted examination of the metabolic differences in cerebrospinal fluid samples from subjects having different cognitive status related to Alzheimer's disease progression and revealed possible metabolic disease progression biomarkers.

\section{In Vitro Manipulation of Neural Cells: Lab-on-Chip Platforms}

In recent years, on-chip systems have been used for neuroscience applications, bringing with them a unique set of capabilities for studying cell-to-cell communication on a small scale (Pearce and Williams, 2007; Wang et al, 2009; Taylor and Jeon, 2010; Croushore and Sweedler, 2013). Lab-on-chip devices readily address the issue of cellto-cell heterogeneity, as they can recreate a network or individual cells of interest for study in a defined environment in vitro. Small culture chamber volumes ( $\mu$ lo $\mathrm{nl}$ ) reduce the dilution encountered in dish-based cultures, improving release collection and leading to better detection of cell-to-cell signaling molecules. In addition, the advent of microvalves (Unger et al, 2000) and complex fluid handling systems has allowed greater control and manipulation of the extracellular space such as the application and removal of chemical stimuli and nutrition factors. Finally, these systems can be coupled to a range of information-rich detection platforms.

What neuroscience questions can be best answered using the unique and growing capabilities of microfluidic lab-onchip devices? These devices have been used to culture a wide range of cells, from mammalian cortical (Kunze et al, 2011) and hippocampal (Millet et al, 2007) neurons to molluscan A. californica neurons (Croushore et al, 2012). Of course, when culturing using an in vitro microenvironment, conditions such as temperature, waste removal, and media replenishment must be taken into account. Several groups have reported designs that improve cell survival in vitro (Tourovskaia et al, 2005; Millet et al, 2007; Millet and Gillette, 2012). Various compartmentalized device designs have enabled studies on axonal transport, injury, and regeneration (Hosmane et al, 2010; Taylor et al, 2010; Majumdar et al, 2011; Taylor and Jeon, 2011). Compartmentalized devices have been used for single molecule tracking of retrograde axonal transport by observing quantum dot-labeled nerve growth factor in endosomes within cultured dorsal root ganglion neurons (Zhang et al, 2010). Innovative microfluidic models of the in vitro blood-brain barrier have drawn attention due to their potential to provide insights into its role in the CNS and drug delivery. These systems, which oftentimes consist of brain endothelial cells cocultured with neurons and/or astrocytes, have been shown to mimic effectively the in vivo environment and regulate the transport efficiencies of rat endothelial cells (Lippmann et al, 2011; Abbott et al, 2012; Prabhakarpandian et al, 2013). Microfluidic models promise to advance our basic understanding of the biological signaling in the blood-brain barrier physiology, knowledge that can have implications in drug discovery research.

Another successful application of lab-on-a-chip devices is the measurement and manipulation of cellular release to understand the conditions that govern it. Control and fluid handling capabilities are achieved by the incorporation of microvalves, which permit selective stimulation of cellular networks or single cells and regulation of the stimulation duration. Several groups have instituted precise chemical stimulations of cells into devices (Sabounchi et al, 2006; Jo et al, 2007). More recently, our group designed a system that used microvalves to control the stimulation of 
low-density cultured neurons within a device (Croushore et al, 2012). A difference in the onset of neuropeptide release was observed for two different chemical stimulations by increasing the duration of chemical stimulation to the cellular network maintained in the device.

A number of lab-on-a-chip applications have focused efforts toward improving signaling molecule detection, including sample preparation on chip (Wei et al, 2010), surface modifications (Jo et al, 2007; Zhong et al, 2012), and on-chip detection (Dishinger et al, 2009). The Kennedy group (Dishinger et al, 2009) reported an automated approach that quantified insulin release from 15 single islet cells using an on-chip electrophoresis channel and an immune assay for detection. We reported a microfluidic system with $\mathrm{C} 18$ functionalized channels to capture and quantify neuropeptide release on-chip with MS detection (Zhong et al, 2012). Rather than quantifying the peptide level via MS peak height, the length of the channel producing appreciable peptide signal from adsorption was used as a measure of peptide amount in release. A linear relationship between peptide amount and band length has been suggested by prior modeling and validated using known neuropeptides.

An advantage of lab-on-chip systems is their fully controllable integration and ability to function as highthroughput chemical screening tools (Livak-Dahl et al, 2011). The use of these devices is gaining popularity for investigations of chemical stimuli on live cells and even entire small organisms such as the nematode Caenorhabditis elegans. A complex, droplet-based microfluidic device integrated with a floatage-based trap array and a tapered immobilization channel array coupled to fluorescence imaging was used in a pharmacological evaluation of neurotoxins on whole-animal mobility, neuron degeneration, and oxidative stress in individual C. elegans (Shi et al, 2010). Another microfluidic device combined with in vivo optical neurophysiology has been used to study proprioceptive properties in the worm motor circuit (Wen et al, 2012). A simpler combination of a microfluidic system with optical microscopy allowed monitoring of the male response to hermaphrodite-conditioned medium containing mating signals (Chung et al, 2011).

\section{Chemical Maps with Mass Spectrometry Imaging}

Non-optical imaging has become an important tool in brain research. Widely used noninvasive technologies for visualization of brain structures (computer-assisted tomography, laser Doppler ultrasound, magnetic resonance imaging) and function (positron emission tomography, diffusion tensor magnetic resonance imaging, electroencephalography and functional magnetic resonance imaging) provide diagnostic information on a range of neurological conditions and therapy effects. MS-based chemical imaging, in contrast, is a cutting edge tool for laboratory neuroscience research that interrogates and catalogs various classes of physiologically important molecules in brain samples, and provides their location, amounts, and temporal dynamics. However, it is both invasive and destructive to the sample. Mass spectrometry imaging (MSI) offers unmatched information content and high throughput and is suitable for chemical imaging of metabolites, transmitters, lipid, peptides, and even proteins in entire brain sections or specific brain region sections, cultured cells of any origin, and in vitro reconstructed neuronal networks.

Although most methods in microanalysis experience a bottleneck in throughput because of sampling, MSI conveniently eliminates the need for microdissection/ extraction/purification steps; the approach can be used to assay defined tissue regions, individual cells, and subcellular domains from conventional tissue sections. Just like MS profiling, MSI generates direct molecular/structural information and spatial localization within the sample. The quality of the chemical map depends on the resolution parameters for mass and space. Mass resolution determines the chemical specificity and accuracy of the measurement, whereas spatial resolution, defined as lateral and depth, specifies the level of morphological detail attainable by a particular MSI technique. Depending on the ionization technique used, the spatial resolution obtained from MSI can be as small as $50 \mathrm{~nm}$ (Klitzing et al, 2013), allowing for single-cell and subcellular chemical mapping, although oftentimes the resolution is much less. Refining spatial resolution capabilities to obtain a more accurate cellular localization of compounds of interest drives the development of improved systems. A tradeoff of better spatial resolution is that there are fewer molecules within the sample spot, leading to fewer analytes being detected.

Although a number of approaches using MSI have been developed (Chen and Li, 2010; Verhaert et al, 2010; Janfelt and Norgaard, 2012; Vismeh et al, 2012), MALDI and secondary ion mass spectrometry (SIMS) are the most widely used ionization methods, each well suited to specific classes of analytes. Most recently, MALDI MSI has been used to create localization maps for neuropeptides with resolutions ranging from 20 to $100 \mu \mathrm{m}$ in the nervous system from several invertebrate models (Zimmerman et al, 2009; Chen et al, 2010; Jia et al, 2012; Mark et al, 2012; Ye et al, 2013), as well as from mammals (Monroe et al, 2008) and from neuronal cell cultures (Zimmerman et al, 2011). Owing to the larger size of invertebrate neurons, de novo sequencing of novel peptides has been possible in MALDI MSI studies (Chen et al, 2010; Jia et al, 2012). Chemical maps of bioactive compounds facilitate functional insights, even in complex organisms. For example, region-specific distribution profiles of neuropeptides in the brain of an animal model of Parkinson's disease by MALDI MSI revealed a correlation between dyskinesia severity and levels of des-tyrosine $\alpha$-neoendorphin in the striatum (Ljungdahl et al, 2011). In another study, the neurochemical response to cocaine was investigated (Uys et al, 2010). Even though MALDI MSI is less common for the analysis of lowmolecular-weight compounds due to chemical interferences from matrix ions, Sugiura et al (2012) studied acetylcholine 
distributions in the mouse hippocampus and spinal cord on the $50 \mu \mathrm{m}$ scale. With atmospheric pressure MALDI MSI, the Spengler group (Guenther et al, 2011) demonstrated neuropeptide imaging of the mouse pituitary gland at the cellular scale ( $5 \mu \mathrm{m}$ spatial resolution), along with structural verification by tandem MS for some of the detected peptides.

In contrast to MALDI, SIMS is a matrix-free approach in which a specimen, such as a tissue section, is sputtered with a focused primary ion beam that ejects secondary ions from the surface of the sample. The secondary ions are then guided into a mass analyzer for measurements. SIMS ionization is more energetic and so fragments larger molecules, limiting its application to small molecules (typically less than $800 \mathrm{Da}$ ), but achieves higher spatial resolution than MALDI. SIMS MSI is often used to investigate the subcellular localization of lipids and lipophilic species in brain sections and cultured neurons (Passarelli and Winograd, 2011; Tucker et al, 2012; Passarelli et al, 2013). Other applications of SIMS MSI for the analysis of biological samples are thoroughly reviewed elsewhere (Lanni et al, 2012). For further reading on the strengths, weaknesses, and complementarity of existing MSI methods, we recommend two recent comprehensive reviews (Vickerman, 2011; Trim et al, 2012).

\section{FUTURE RESEARCH DIRECTIONS}

Small-volume analysis has experienced tremendous technical progress in the past decade. We envision it becoming an essential element in modern neurotherapeutic discovery, with growth anticipated in fundamental neuroscience, diagnostics, and drug development. In terms of fundamental research, identifying the molecular pathways involved in neurological disorders and psychiatric disease presents a challenge in neuroscience, one that will be best addressed by methods that supply high chemical information content, spatially resolved data, and temporal information on chemical dynamics.

MS-based platforms for label-free profiling and imaging, and single-cell applications in particular, can contribute to a better understanding of the complexity of the neuronal circuit and pathway. Future work will focus on the development of improved sampling, increasing mass and spatial resolution to enable MSI, and identification of bioactive molecule localization at the subcellular scale. In fact, MS and MSI, in particular, have yet to realize their potential to complement existing gene expression and immunohistochemical maps (such as those found in the Allen Brain Atlas, http://www.brain-map.org/) by generating maps of final gene products. This will be especially useful for neuropeptides whose sequences are often inferred from their mRNA transcripts. Peptides are created from gene products that have alternate splicing, post-transcriptional proteolytic processing, and other modifications that cannot yet be reliably predicted from genetic information, and thus have to be investigated on the peptide level using direct detection methods such as MSI.

The ability to correlate behavior with dynamic changes in native bioactive compounds and drugs from precise brain locations should accelerate the development of new treatments for neurological diseases. Methods will become available that enable cerebral microdialysis to provide continuous sampling of endogenous and exogenous molecules of interest from the extracellular fluid of the brain in freely moving animals, and perhaps even from patients with several types of brain injury. Innovative research using the successful hyphenation of microdialysis to sensitive detection modalities has demonstrated the great potential of this approach for achieving real-time quantitative monitoring of metabolites and neurotransmitters, and for its applicability in neuropharmacokinetic drug studies. In conjunction with microdialysis, CE and MS can be used for identification of potential biomarkers in cerebrospinal fluid for clinical diagnosis of relevant disorders, and for monitoring therapeutic interventions. To enable these approaches for use in medical settings, future efforts should concentrate on miniaturization of sampling probes, making cerebral microdialysis less traumatic-just as lumbar puncture has become-and thus more applicable to human volunteers for facilitation of drug testing and discovery. A limitation in the small-volume analysis of cerebral fluid samples has been the dispersion of the analyte band during transfer from the dialysis probe to the analytical system, which limits temporal resolution. Although exciting progress has been reported with the advent of segmented flow microdialysis and low-flow push-pull perfusion, further improvements in temporal resolution of in vivo monitoring methods are required to follow accurately neurochemical dynamics.

Finally, microfluidic devices and lab-on-chip platforms have become more widely used for in vivo and in vitro analyses of signaling compounds, as they incorporate multiple functions, including cell culture, stimulation, separation, and detection, at better sensitivity than bulk analysis methods. The portability and small footprint of lab-on-chip devices have the potential to revolutionize high-content screening, allowing clinical use of cell-based assays for determining drug efficacy and toxicity. The translation of exciting original ideas into medical applications requires standardization of protocols, validation of day-to-day reproducibility, and robustness of microfluidic systems, which remains a significant and ongoing endeavor.

\section{FUNDING AND DISCLOSURE}

This material is based on work supported by Award Number P30 DA018310 from the National Institute on Drug Abuse, NS031609 from the National Institute of Neurological Disorders and Stroke, and the NSF Division of Chemistry under Grant CHE-11-11705 (with cofunding from the Division of Biological Infrastructure). The content is solely the responsibility of the authors and does not necessarily 
represent the official views of the award agencies. The remaining authors declare no conflict of interest.

\section{ACKNOWLEDGEMENTS}

We thank Professor Leonid Moroz for providing the example of an in situ staining image. The SEM images were obtained using the field-emission environmental scanning electron microscope (XL30 ESEM-FEG; Philips/ FEI, Hillsboro OR; NSF DBI-9871103) in the Microscopy Suite at the Beckman Institute for Advanced Science and Technology, part of the University of Illinois at UrbanaChampaign. We also thank Dr Scott Robinson for his assistance.

\section{REFERENCES}

Abbott NJ, Dolman DE, Drndarski S, Fredriksson SM (2012). An improved in vitro blood-brain barrier model: rat brain endothelial cells co-cultured with astrocytes. Methods Mol Biol 814: 415-430.

Agnati LF, Guidolin D, Guescini M, Genedani S, Fuxe K (2010). Understanding wiring and volume transmission. Brain Res Rev 64: 137-159.

Alberts B, Bray D, Lewis J, Raff M, Roberts K, Watson JD (1994). Molecular Biology of the Cell. Garland Science.

Alothman ZA, Dawod M, Kim J, Chung DS (2012). Single-drop microextraction as a powerful pretreatment tool for capillary electrophoresis: a review. Anal Chim Acta 739: 14-24. Descriptions and insights into an elegant small-volume sample cleanup and preconcentration approach used before a microseparation. The review focuses on theoretical background, development, advances, and new methodologies for droplet-based microextraction when coupled to $\mathrm{CE}$.

Arafah K, Croix D, Vizioli J, Desmons A, Fournier I, Salzet M (2013). Involvement of nitric oxide through endocannabinoids release in microglia activation during the course of CNS regeneration in the medicinal leech. Glia 61: 636-649.

Barberis A, Petrini EM, Mozrzymas JW (2011). Impact of synaptic neurotransmitter concentration time course on the kinetics and pharmacological modulation of inhibitory synaptic currents. Front Cell Neurosci 5: 6.

Behrens HL, Li L (2010). Monitoring neuropeptides in vivo via microdialysis and mass spectrometry. Methods $\mathrm{Mol}$ Biol 615: 57-73. A detailed protocol for in vitro microdialysis with LC-MS quantification, with descriptions of analyte recovery, in vivo microdialysis, dialysate sample preparation, and MS analyses of neuropeptides from microdialysates that can be readily applied to a range of biological measurements.

Berglund EC, Kuklinski NJ, Karagunduz E, Ucar K, Hanrieder J, Ewing AG (2013). Freeze-drying as sample preparation for micellar electrokinetic capillary chromatography-electrochemical separations of neurochemicals in Drosophila brains. Anal Chem 85: 2841-2846.

Bolton E, Wang Y, Thiessen PA, Bryant SH (2008). PubChem: Integrated Platform of Small Molecules and Biological Activities. Chapter 12 In: Annual Reports in Computational Chemistry vol. 4. American Chemical Society: Washington, DC.

Burchett SA, Hicks TP (2006). The mysterious trace amines: protean neuromodulators of synaptic transmission in mammalian brain. Prog Neurobiol 79: 223-246.

Cecala C, Rubakhin SS, Mitchell JW, Gillette MU, Sweedler JV (2012). A hyphenated optical trap capillary electrophoresis laser induced native fluorescence system for single-cell chemical analysis. Analyst 137: 2965-2972.

Cecala C, Sweedler JV (2012). Sampling techniques for single-cell electrophoresis. Analyst 137: 2922-2929. A review of sampling approaches for the effective isolation of specific cells, with the approaches ranging from manual isolation, optical traps, cell sorting, and microfluidic manipulations.

Chen D, Du W, Liu Y, Liu W, Kuznetsov A, Mendez FE et al (2008). The chemistrode: a droplet-based microfluidic device for stimulation and recording with high temporal, spatial, and chemical resolution. Proc Natl Acad Sci USA 105: 16843-16848.

Chen R, Jiang X, Conaway MC, Mohtashemi I, Hui L, Viner R et al (2010). Mass spectral analysis of neuropeptide expression and distribution in the nervous system of the lobster Homarus americanus. J Proteome Res 9: 818-832.

Chen R, Li L (2010). Mass spectral imaging and profiling of neuropeptides at the organ and cellular domains. Anal Bioanal Chem 397: 3185-3193.
Christie AE, Stemmler EA, Dickinson PS (2010). Crustacean neuropeptides. Cell Mol Life Sci 67: 4135-4169.

Chung K, Zhan M, Srinivasan J, Sternberg PW, Gong E, Schroeder FC et al (2011). Microfluidic chamber arrays for whole-organism behavior-based chemical screening. Lab Chip 11: 3689-3697.

Cooper GM, Hausman RE (2009). The Cell: A Molecular Approach. Sinauer Associates.

Croushore CA, Supharoek S-A, Lee CY, Jakmunee J, Sweedler JV (2012). Microfluidic device for the selective chemical stimulation of neurons and characterization of peptide release with mass spectrometry. Anal Chem 84: 9446-9452.

Croushore CA, Sweedler JV (2013). Microfluidic systems for studying neurotransmitters and neurotransmission. Lab Chip 13: 1666-1676.

Cui Q, Lewis IA, Hegeman AD, Anderson ME, Li J, Schulte CF et al (2008). Metabolite identification via the Madison Metabolomics Consortium Database. Nat Biotechnol 26: 162-164.

Dada OO, Essaka DC, Hindsgaul O, Palcic MM, Prendergast J, Schnaar RL et al (2011). Nine orders of magnitude dynamic range: picomolar to millimolar concentration measurement in capillary electrophoresis with laser induced fluorescence detection employing cascaded avalanche photodiode photon counters. Anal Chem 83: 2748-2753.

Dishinger JF, Reid KR, Kennedy RT (2009). Quantitative monitoring of insulin secretion from single Islets of Langerhans in parallel on a microfluidic chip. Anal Chem 81: 3119-3127.

Dulcis D, Spitzer NC (2008). Illumination controls differentiation of dopamine neurons regulating behaviour. Nature 456: 195-201.

Emmert-Buck MR, Bonner RF, Smith PD, Chuaqui RF, Zhuang Z, Goldstein SR et al (1996). Laser capture microdissection. Science 274: 998-1001.

Espina V, Wulfkuhle JD, Calvert VS, VanMeter A, Zhou WD, Coukos G et al (2006). Laser-capture microdissection. Nat Protoc 1: 586-603.

Essaka DC, Prendergast J, Keithley RB, Palcic MM, Hindsgaul O, Schnaar RL et al (2012). Metabolic cytometry: capillary electrophoresis with two-color fluorescence detection for the simultaneous study of two glycosphingolipid metabolic pathways in single primary neurons. Anal Chem 84: 2799-2804.

Fahy E, Sud M, Cotter D, Subramaniam S (2007). LIPID MAPS online tools for lipid research. Nucleic Acids Res 35: W606-612.

Fan Y, Rubakhin SS, Sweedler JV (2011). Collection of peptides released from single neurons with particle-embedded monolithic capillaries followed by detection with matrix-assisted laser desorption/ionization mass spectrometry. Anal Chem 83: 9557-9563.

Fang H, Vickrey TL, Venton BJ (2011). Analysis of biogenic amines in a single Drosophila larva brain by capillary electrophoresis with fast-scan cyclic voltammetry detection. Anal Chem 83: 2258-2264.

Fossat P, Turpin FR, Sacchi S, Dulong J, Shi T, Rivet JM et al (2012). Glial D-serine gates NMDA receptors at excitatory synapses in prefrontal cortex. Cereb Cortex 22: 595-606.

Fuller RR, Moroz LL, Gillette R, Sweedler JV (1998). Single neuron analysis by capillary electrophoresis with fluorescence spectroscopy. Neuron 20: 173-181.

Gholipour Y, Erra-Balsells R, Hiraoka K, Nonami H (2013). Living cell manipulation, manageable sampling, and shotgun picoliter electrospray mass spectrometry for profiling metabolites. Anal Biochem 433: 70-78.

Grundmann M, Matysik FM (2011). Fast capillary electrophoresis-time-of-flight mass spectrometry using capillaries with inner diameters ranging from 75 to 5 um. Anal Bioanal Chem 400: 269-278.

Guenther S, Römpp A, Kummer W, Spengler B (2011). AP-MALDI imaging of neuropeptides in mouse pituitary gland with $5 \mu \mathrm{m}$ spatial resolution and high mass accuracy. Int J Mass Spectrom 305: 228-237.

Guihen E, O'Connor WT (2010). Capillary and microchip electrophoresis in microdialysis: recent applications. Electrophoresis 31: 55-64. Highlights the concepts of coupling microdialysis sample collection to microscale electrophoretic-based separations, including advantages, challenges, and applications in medicine and neuroscience.

Hastings J, de Matos P, Dekker A, Ennis M, Harsha B, Kale N et al (2013). The ChEBI reference database and ontology for biologically relevant chemistry: enhancements for 2013. Nucleic Acids Res 41: D456-D463.

Hatcher NG, Zhang X, Stuart JN, Moroz LL, Sweedler JV, Gillette R (2008). 5-HT and 5-HT-SO4, but not tryptophan or 5-HIAA levels in single feeding neurons track animal hunger state. J Neurochem 104: 1358-1363.

Hillenkamp F, Peter-Katalinic J (eds). (2007). MALDI MS: A Practical Guide to Instrumentation, Methods and Applications. Wiley-Blackwell.

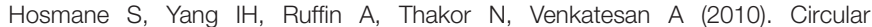
compartmentalized microfluidic platform: Study of axon-glia interactions. Lab Chip 10: 741-747. 
Ibanez C, Simo C, Martin-Alvarez PJ, Kivipelto M, Winblad B, Cedazo-Minguez A et al (2012). Toward a predictive model of Alzheimer's disease progression using capillary electrophoresis-mass spectrometry metabolomics. Anal Chem 84: 8532-8540.

Iyer EP, Cox DN (2010). Laser capture microdissection of Drosophila peripheral neurons. J Vis Exp 39: 2016.

Janfelt C, Norgaard AW (2012). Ambient mass spectrometry imaging: a comparison of desorption ionization by sonic spray and electrospray. J Am Soc Mass Spectrom 23: 1670-1678.

Jarecki JL, Andersen K, Konop CJ, Knickelbine JJ, Vestling MM, Stretton AO (2010). Mapping neuropeptide expression by mass spectrometry in single dissected identified neurons from the dorsal ganglion of the nematode Ascaris suum. ACS Chem Neurosci 1: 505-519.

Jia C, Hui L, Cao W, Lietz CB, Jiang X, Chen R et al (2012). High-definition de novo sequencing of crustacean hyperglycemic hormone $(\mathrm{CHH})$-family neuropeptides. Mol Cell Proteomics 11: 1951-1964.

Jimenez CR, Spijker S, de Schipper S, Lodder JC, Janse CK, Geraerts WP et al (2006). Peptidomics of a single identified neuron reveals diversity of multiple neuropeptides with convergent actions on cellular excitability. J Neurosci 26: 518-529.

Jimenez CR, van Veelen PA, Li KW, Wildering WC, Geraerts WP, Tjaden UR et al (1994). Neuropeptide expression and processing as revealed by direct matrix-assisted laser desorption ionization mass spectrometry of single neurons. J Neurochem 62: 404-407.

Jing J, Sweedler JV, Cropper EC, Alexeeva V, Park JH, Romanova EV et al (2010). Feedforward compensation mediated by the central and peripheral actions of a single neuropeptide discovered using representational difference analysis. J Neurosci 30: 16545-16558.

Jo K, Heien ML, Thompson LB, Zhong M, Nuzzo RG, Sweedler JV (2007). Mass spectrometric imaging of peptide release from neuronal cells within microfluidic devices. Lab Chip 7: 1454-1460.

Kanehisa M, Goto S, Sato Y, Furumichi M, Tanabe M (2012). KEGG for integration and interpretation of large-scale molecular data sets. Nucleic Acids Res 40: D109-D114.

Katona I, Freund TF (2012). Multiple functions of endocannabinoid signaling in the brain. Annu Rev Neurosci 35: 529-558.

Klitzing HA, Weber PK, Kraft ML (2013). Secondary ion mass spectrometry imaging of biological membranes at high spatial resolution. Methods Mol Biol 950 : 483-501.

Knolhoff AM, Nautiyal KM, Nemes P, Kalachikov S, Morozova I, Silver R et al (2013). Combining small-volume metabolomic and transcriptomic approaches for assessing brain chemistry. Anal Chem 85: 3136-3143.

Kuklinski NJ, Berglund EC, Engelbrektsson J, Ewing AG (2010). Biogenic amines in microdissected brain regions of Drosophila melanogaster measured with micellar electrokinetic capillary chromatography-electrochemical detection. Anal Chem 82: 7729-7735.

Kunze A, Meissner R, Brando S, Renaud P (2011). Co-pathological connected primary neurons in a microfluidic device for Alzheimer studies. Biotechnol Bioeng 108: 2241-2245.

Lachenal G, Pernet-Gallay K, Chivet M, Hemming FJ, Belly A, Bodon G et al (2011). Release of exosomes from differentiated neurons and its regulation by synaptic glutamatergic activity. Mol Cell Neurosci 46: 409-418.

Lanni EJ, Rubakhin SS, Sweedler JV (2012). Mass spectrometry imaging and profiling of single cells. J Proteome Res 75: 5036-5051. The application of mass spectrometry imaging and profiling to cell and subcellular sampling, including details on analytical instrumentation, methods that enable sample preparation, the required data analyses steps, and advances needed to reliably visualize the distributions of intact molecules at micron and submicron resolutions.

Lapainis T, Rubakhin SS, Sweedler JV (2009). Capillary electrophoresis with electrospray ionization mass spectrometric detection for single-cell metabolomics. Anal Chem 81: 5858-5864.

Li KW, Smit AB (2010). Mass spectrometric analysis of molluscan neuropeptides. Methods Mol Biol 615: 49-56.

Li L, Garden RW, Sweedler JV (2000). Single-cell MALDI: a new tool for direct peptide profiling. Trends Biotechnol 18: 151-160.

Li L, Sweedler JV (2008). Peptides in the brain: mass spectrometry-based measurement approaches and challenges. Annu Rev Anal Chem 1: 451-483.

Lin S-L, Bai H-Y, Lin T-Y, Fuh M-R (2012). Microfluidic chip-based liquid chromatography coupled to mass spectrometry for determination of small molecules in bioanalytical applications. Electrophoresis 33: 635-643.

Lin S-L, Bai H-Y, Lin T-Y, Fuh M-R (2012). Microfluidic chip-based liquid chromatography coupled to mass spectrometry for determination of small molecules in bioanalytical applications. Electrophoresis 33: 635-643.
Lin YQ, Trouillon R, Safina G, Ewing AG (2011). Chemical analysis of single cells. Anal Chem 83: 4369-4392.

Lippmann ES, Weidenfeller C, Svendsen CN, Shusta EV (2011). Blood-brain barrier modeling with co-cultured neural progenitor cell-derived astrocytes and neurons. J Neurochem 119: 507-520.

Livak-Dahl E, Sinn I, Burns M (2011). Microfluidic chemical analysis systems. Annu Rev Chem Biomol Eng 2: 325-353. An overview of the potential of microfluidic devices in life science research. Attention is given to design concepts, principles of fabrication, flow control, compartmentalization, integration, and readout.

Ljungdahl A, Hanrieder J, Falth M, Bergquist J, Andersson M (2011). Imaging mass spectrometry reveals elevated nigral levels of dynorphin neuropeptides in L-DOPA-induced dyskinesia in rat model of Parkinson's disease. PLOS One 6: e25653.

Lowry $\mathrm{OH}$ (1953). The quantitative histochemistry of the brain; histological sampling. J Histochem Cytochem 1: 420-428.

Majumdar D, Gao Y, Li D, Webb DJ (2011). Co-culture of neurons and glia in a novel microfluidic platform. J Neurosci Methods 196: 38-44.

Mark L, Maasz G, Pirger Z (2012). High resolution spatial distribution of neuropeptides by MALDI imaging mass spectrometry in the terrestrial Snail, Helix pomatia. Acta Biol Hung 63: 113-122.

Mellors JS, Black WA, Chambers AG, Starkey JA, Lacher NA, Ramsey JM (2013). A hybrid capillary/microfluidic system for comprehensive online liquid chromatography-capillary electrophoresis-electrospray ionization-mass spectrometry. Anal Chem 85: 4100-4106.

Mellors JS, Gorbounov V, Ramsey RS, Ramsey JM (2008). Fully integrated glass microfluidic device for performing high-efficiency capillary electrophoresis and electrospray ionization mass spectrometry. Anal Chem 80: 6881-6887.

Merighi A, Salio C, Ferrini F, Lossi L (2011). Neuromodulatory function of neuropeptides in the normal CNS. J Chem Neuroanat 42: 276-287.

Micheva KD, Busse B, Weiler NC, O'Rourke N, Smith SJ (2010). Single-synapse analysis of a diverse synapse population: proteomic imaging methods and markers. Neuron 68: 639-653.

Millet LJ, Gillette MU (2012). New perspectives on neuronal development via microfluidic environments. Trends Neurosci 35: 752-761. A fun to read review about the interface of engineering technologies with biological methodologies for the development of microenvironments that allow the maintenance and study of brain cells and circuits in microculture.

Millet LJ, Stewart ME, Sweedler JV, Nuzzo RG, Gillette MU (2007). Microfluidic devices for culturing primary mammalian neurons at low densities. Lab Chip 7: 987-994

Moini M (2013). High-throughput capillary electrophoresis-mass spectrometry: from analysis of amino acids to analysis of protein complexes. Methods Mol Biol 984: 79-119.

Monroe EB, Annangudi SP, Hatcher NG, Gutstein HB, Rubakhin SS, Sweedler JV (2008). SIMS and MALDI MS imaging of the spinal cord. Proteomics 8 : 3746-3754

Moroz LL, Edwards JR, Puthanveettil SV, Kohn AB, Ha T, Heyland A et al (2006). Neuronal transcriptome of Aplysia: neuronal compartments and circuitry. Cell 127: $1453-1467$

Nandi P, Desai DP, Lunte SM (2010). Development of a PDMS-based microchip electrophoresis device for continuous online in vivo monitoring of microdialysis samples. Electrophoresis 31: 1414-1422.

Nautiyal KM, Dailey CA, Jahn JL, Rodriquez E, Son NH, Sweedler JV et al (2012). Serotonin of mast cell origin contributes to hippocampal function. Eur $\mathrm{J}$ Neurosc 36: 2347-2359

Nemes P, Knolhoff AM, Rubakhin SS, Sweedler JV (2011). Metabolic differentiation of neuronal phenotypes by single-cell capillary electrophoresis-electrospray ionization-mass spectrometry. Anal Chem 83: 6810-6817.

Nemes P, Knolhoff AM, Rubakhin SS, Sweedler JV (2012). Single-cell metabolomics: changes in the metabolome of freshly isolated and cultured neurons. ACS Chem Neurosci 3: 782-792.

Neupert S, Fusca D, Schachtner J, Kloppenburg P, Predel R (2012). Toward a single-cell-based analysis of neuropeptide expression in Periplaneta americana antennal lobe neurons. J Comp Neurol 520: 694-716.

Neupert S, Johard HA, Nassel DR, Predel R (2007). Single-cell peptidomics of Drosophila melanogaster neurons identified by Gal4-driven fluorescence. Anal Chem 79: 3690-3694.

Neupert S, Predel R (2010). Peptidomic analysis of single identified neurons. Methods Mol Biol 615: 137-144.

Neupert S, Rubakhin Stanislav S, Sweedler Jonathan V (2012). Targeted single-cell microchemical analysis: MS-based peptidomics of individual paraformaldehydefixed and immunolabeled neurons. Chem Biol 19: 1010-1019.

Nilsson J, Evander M, Hammarstrom B, Laurell T (2009). Review of cell and particle trapping in microfluidic systems. Anal Chim Acta 649: 141-157. 
Omiatek DM, Santillo MF, Heien ML, Ewing AG (2009). Hybrid capillary-microfluidic device for the separation, lysis, and electrochemical detection of vesicles. Anal Chem 81: 2294-2302.

Passarelli MK, Ewing AG, Winograd N (2013). Single-cell lipidomics: Characterizing and imaging lipids on the surface of individual Aplysia californica neurons with cluster secondary ion mass spectrometry. Anal Chem 85: 2231-2238.

Passarelli MK, Winograd N (2011). Lipid imaging with time-of-flight secondary ion mass spectrometry (ToF-SIMS). Biochim Biophys Acta 1811: 976-990.

Pearce TM, Williams JC (2007). Microtechnology: meet neurobiology. Lab Chip 7: 30-40.

Pentoney Jr SL, Sweedler JV (1997). Handbook of Capillary Electrophoresis. CRC Press: Boca Raton, FL, USA.

Pineiro R, Falasca M (2012). Lysophosphatidylinositol signalling: new wine from an old bottle. Biochim Biophys Acta Mol Cell Biol Lipids 1821: 694-705.

Potgieter K, Hatcher NG, Gillette R, McCrohan CR (2010). Nitric oxide potentiates CAMP-gated cation current by intracellular acidification in feeding neurons of Pleurobranchaea. J Neurophysiol 104: 742-745.

Powell PR, Paxon TL, Han KA, Ewing AG (2005). Analysis of biogenic amine variability among individual fly heads with micellar electrokinetic capillary chromatography-electrochemical detection. Anal Chem 77: 6902-6908.

Prabhakarpandian B, Shen MC, Nichols JB, Mills IR, Sidoryk-Wegrzynowicz M, Aschner M et al (2013). SyM-BBB: a microfluidic blood brain barrier model. Lab Chip 13: 1093-1101.

Rainville P (2011). Microfluidic LC-MS for analysis of small-volume biofluid samples: where we have been and where we need to go. Bioanalysis 3: 1-3.

Raj A, van Oudenaarden A (2008). Nature, vurture, or chance: stochastic gene expression and its consequences. Cell 135: 216-226.

Ramsay LM, Dickerson JA, Dada O, Dovichi NJ (2009). Femtomolar concentration detection limit and zeptomole mass detection limit for protein separation by capillary isoelectric focusing and laser-induced fluorescence detection. Anal Chem 81: 1741-1746.

Romanova EV, Fosser KA, Rubakhin SS, Nuzzo RG, Sweedler JV (2004). Engineering the morphology and electrophysiological parameters of cultured neurons by microfluidic surface patterning. FASEB J 18: 1267-1269.

Romanova EV, Hatcher NG, Rubakhin SS, Sweedler JV (2009). Characterizing intercellular signaling peptides in drug addiction. Neuropharmacology 56(Suppl 1): 196-204

Romanova EV, Mckay N, Weiss KR, Sweedler JV, Koester J (2007). Autonomic control network active in Aplysia during locomotion includes neurons that express splice variants of R15-neuropeptides. J Neurophysiol 97 : 481-491.

Romanova EV, Sasaki K, Alexeeva V, Vilim FS, Jing J, Richmond TA et al (2012). Urotensin II in invertebrates: from structure to function in Aplysia californica. PLoS One 7: e48764.

Rubakhin SS, Churchill JD, Greenough WT, Sweedler JV (2006). Profiling signaling peptides in single mammalian cells using mass spectrometry. Anal Chem 78: 7267-7272.

Rubakhin SS, Greenough WT, Sweedler JV (2003). Spatial profiling with MALDI MS: distribution of neuropeptides within single neurons. Anal Chem 75: 5374-5380.

Rubakhin SS, Sweedler JV (2008). Quantitative measurements of cell-cell signaling peptides with single-cell MALDI MS. Anal Chem 80: 7128-7136.

Sabounchi P, lonescu-Zanetti C, Chen R, Karandikar M, Seo J, Lee LP (2006). Softstate biomicrofluidic pulse generator for single cell analysis. Appl Phys Lett 88: 183901

Samano C, Cifuentes F, Morales MA (2012). Neurotransmitter segregation: functional and plastic implications. Prog Neurobiol 97: 277-287.

Scanlan C, Shi T, Hatcher NG, Rubakhin SS, Sweedler JV (2010). Synthesis, accumulation, and release of D-aspartate in the Aplysia californica CNS. J Neurochem 115: 1234-1244.

Sellick CA, Hansen R, Maqsood AR, Dunn WB, Stephens GM, Goodacre R et al (2009). Effective quenching processes for physiologically valid metabolite profiling of suspension cultured mammalian cells. Anal Chem 81: 174-183.

Sharp T, Zetterström T (2006). What did we learn from microdialysis? In: Westerink BHC, Cremers TIFH (eds) Handbook of Microdialysis, Volume 16: Methods, Applications and Perspectives (Handbook of Behavioral Neuroscience) Vol 6 (Academic Press: New York, NY, USA, pp 5-16.

Shi W, Wen H, Lu Y, Shi Y, Lin B, Qin J (2010). Droplet microfluidics for characterizing the neurotoxin-induced responses in individual Caenorhabditis elegans. Lab Chip 10: 2855-2863.

Simó C, García-Cañas V, Cifuentes A (2010). Chiral CE-MS. Electrophoresis 31: 1442-1456.

Slaney TR, Nie J, Hershey ND, Thwar PK, Linderman J, Burns MA et al (2011). Push-pull perfusion sampling with segmented flow for high temporal and spatial resolution in vivo chemical monitoring. Anal Chem 83: 5207-5213.
Smith CA, O'Maille G, Want EJ, Qin C, Trauger SA, Brandon TR et al (2005). METLIN - A metabolite mass spectral database. Ther Drug Monit 27: 747-751.

Snijder B, Pelkmans L (2011). Origins of regulated cell-to-cell variability. Nat Rev Mol Cell Biol 12: 119-125. A nice discussion concerning the origins of cell to cell variability, and that it results from complex regulatory networks and cell population context. The article advocates the need for comprehensive quantitative analysis at single cell level using current technologies.

Song P, Hershey ND, Mabrouk OS, Slaney TR, Kennedy RT (2012). Mass spectrometry 'sensor' for in vivo acetylcholine monitoring. Anal Chem 84: 4659-4664.

Squires LN, Jakubowski JA, Stuart JN, Rubakhin SS, Hatcher NG, Kim WS et al (2006). Serotonin catabolism and the formation and fate of 5-hydroxyindole thiazolidine carboxylic acid. J Biol Chem 281: 13463-13470.

Stern JE, Filosa JA (2013). Bidirectional neuro-glial signaling modalities in the hypothalamus: role in neurohumoral regulation. Auton Neurosci pii: S1566070200003-00009 51-60.

Stockholm D, Benchaouir R, Picot J, Rameau P, TMA Neildez, Landini G et al (2007). The origin of phenotypic heterogeneity in a clonal cell population in vitro. PLoS One 2: e394.

Sugiura Y, Zaima N, Setou M, Ito S, Yao I (2012). Visualization of acetylcholine distribution in central nervous system tissue sections by tandem imaging mass spectrometry. Anal Bioanal Chem 403: 1851-1861.

Sun XF, Kelly RT, Tang KQ, Smith RD (2010). Ultrasensitive nanoelectrospray ionization-mass spectrometry using poly(dimethylsiloxane) microchips with monolithically integrated emitters. Analyst 135: 2296-2302.

Suzuki M, Tanaka H, Iribe Y (2009). Detection and collection system of target single cell based on respiration and metabolic activity. Int Symp Micro-NanoMechatron Hum Sci 310-315.

Swain PS, Elowitz MB, Siggia ED (2002). Intrinsic and extrinsic contributions to stochasticity in gene expression. Proc Natl Acad Sci USA 99: 12795-12800.

Szoko E, Tabi T (2010). Analysis of biological samples by capillary electrophoresis with laser induced fluorescence detection. J Pharm Biomed Anal 53: 1180-1192.

Taylor AM, Dieterich DC, Ito HT, Kim SA, Schuman EM (2010). Microfluidic local perfusion chambers for the visualization and manipulation of synapses. Neuron 66: $57-68$.

Taylor AM, Jeon NL (2010). Micro-scale and microfluidic devices for neurobiology. Curr Opin Neurobiol 20: 640-647.

Taylor AM, Jeon NL (2011). Microfluidic and compartmentalized platforms for neurobiological research. Crit Rev Biomed Eng 39: 185-200. The development of microfabricted compartmentalized microfluidic platforms that allow the independent manipulation of axons and dendrites in culture. These devices have a great potential for investigations of axonal transport, synapse formation, and axonal injury/regeneration.

Tourovskaia A, Figueroa-Masot X, Folch A (2005). Differentiation-on-a-chip: a microfluidic platform for long-term cell culture studies. Lab Chip 5: 14-19.

Trim PJ, Djidja MC, Muharib T, Cole LM, Flinders B, Carolan VA et al (2012). Instrumentation and software for mass spectrometry imaging —making the most of what you've got. J Proteome Res 75: 4931-4940.

(with the focus on the application of MALDI, DESI, LAESI, and SIMS instrumentation for imaging applications, and an overview of freely available MSI software, this is a useful resource for low cost upgrade of existing MS instruments to allow MSI).

Trouillon R, Passarelli MK, Wang J, Kurczy ME, Ewing AG (2013). Chemical analysis of single cells. Anal Chem 85: 522-542.

(an overview of new techniques or variations of techniques developed since 2011 for qualitative and quantitative fluorescence, mass spectrometry, mass spectrometry imaging, and electrochemical analysis).

Tucker KR, Li Z, Rubakhin SS, Sweedler JV (2012). Secondary ion mass spectrometry imaging of molecular distributions in cultured neurons and their processes: comparative analysis of sample preparation. J Am Soc Mass Spectrom 23: 1931-1938.

Unger MA, Chou HP, Thorsen T, Scherer A, Quake SR (2000). Monolithic microfabricated valves and pumps by multilayer soft lithography. Science 288: 113-116.

Urban PL, Jefimovs K, Amantonico A, Fagerer SR, Schmid T, Madler S et al (2010). High-density micro-arrays for mass spectrometry. Lab Chip 10: 3206-3209.

Uys JD, Grey AC, Wiggins A, Schwacke JH, Schey KL, Kalivas PW (2010). Matrixassisted laser desorption/ionization tissue profiling of secretoneurin in the nucleus accumbens shell from cocaine-sensitized rats. J Mass Spectrom 45: 97-103.

van den Pol AN (2012). Neuropeptide transmission in brain circuits. Neuron 76 : 98-115.

Verhaert PD, Pinkse MW, Strupat K, Conaway MC (2010). Imaging of similar mass neuropeptides in neuronal tissue by enhanced resolution MALDI MS with an ion trap-Orbitrap hybrid instrument. Methods Mol Biol 656: 433-449. 
Vickerman JC (2011). Molecular imaging and depth profiling by mass spectrometry-SIMS, MALDI or DESI? Analyst 136: 2199-2217. Techniques for label-free molecular imaging are reviewed with attention to the strengths, weaknesses, and complementarity of the three most common MSI techniques-SIMS, MALDI, and DESI mass spectrometry imaging.

Viglio S, Fumagalli M, Ferrari F, Bardoni A, Salvini R, Giuliano S et al (2012). Recent novel MEKC applications to analyze free amino acids in different biomatrices: 2009-2010. Electrophoresis 33: 36-47. An overview of new methodological developments in MEKC such as separation of racemic mixtures in food and complex biological samples, as well as new commercial microfluidic devices.

Vilim FS, Sasaki K, Rybak J, Alexeeva V, Cropper EC, Jing J et al (2010). Distinct mechanisms produce functionally complementary actions of neuropeptides that are structurally related but derived from different precursors. J. Neurosci 30: $131-147$.

Vismeh R, Waldon DJ, Teffera Y, Zhao Z (2012). Localization and quantification of drugs in animal tissues by use of desorption electrospray ionization mass spectrometry imaging. Anal Chem 84: 5439-5445.

Wagner Z, Tabi T, Jako T, Zachar G, Csillag A, Szoko E (2012). Chiral separation and determination of excitatory amino acids in brain samples by CE-LIF using dual cyclodextrin system. Anal Bioanal Chem 404: 2363-2368.

Wang J, Ren L, Li L, Liu W, Zhou J, Yu W et al (2009). Microfluidics: a new cosset for neurobiology. Lab Chip 9: 644-652.

Wang L, Ota N, Romanova EV, Sweedler JV (2011). A novel pyridoxal 5'-phosphate-dependent amino acid racemase in the Aplysia californica central nervous system. J Biol Chem 286: 13765-13774.

Wang M, Roman GT, Perry ML, Kennedy RT (2009). Microfluidic chip for high efficiency electrophoretic analysis of segmented flow from a microdialysis probe and in vivo chemical monitoring. Anal Chem 81: 9072-9078.

Wei H, Li H, Gao D, Lin JM (2010). Multi-channel microfluidic devices combined with electrospray ionization quadrupole time-of-flight mass spectrometry applied to the monitoring of glutamate release from neuronal cells. Analyst 135: 2043-2050

Wen Q, Po MD, Hulme E, Chen S, Liu X, Kwok SW et al (2012). Proprioceptive coupling within motor neurons drives $C$. elegans forward locomotion. Neuron 76: 750-761.

Williams AJ, Ekins S, Tkachenko V (2012). Towards a gold standard: regarding quality in public domain chemistry databases and approaches to improving the situation. Drug Discov Today 17: 685-701.
Wise DD, Shear JB (2006). Quantitation of nicotinamide and serotonin derivatives and detection of flavins in neuronal extracts using capillary electrophoresis with multiphoton-excited fluorescence. J Chromatogr 1111: 153-158.

Wishart DS, Knox C, Guo AC, Eisner R, Young N, Gautam B et al (2009). HMDB: a knowledgebase for the human metabolome. Nucleic Acids Res 37: D603-D610.

Ye H, Hui L, Kellersberger K, Li L (2013). Mapping of neuropeptides in the crustacean stomatogastric nervous system by imaging mass spectrometry. J Am Soc Mass Spectrom 24: 134-147.

Ye H, Xia S, Yu L, Xu X, Zheng C, Xu H et al (2011). Solid-phase extraction-fieldamplified sample injection coupled with CE-ESI-MS for online pre-concentration and quantitative analysis of brain-gut peptides. Electrophoresis 32: 2823-2829.

Ye X, Rubakhin SS, Sweedler JV (2008). Detection of nitric oxide in single cells. Analyst 133: 423-433.

Ye X, Xie F, Romanova EV, Rubakhin SS, Sweedler JV (2010). Production of nitric oxide within the Aplysia californica nervous system. ACS Chem Neurosci 1: 182-193.

Yew JY, Wang Y, Barteneva N, Dikler S, Kutz-Naber KK, Li L et al (2009). Analysis of neuropeptide expression and localization in adult Drosophila melanogaster central nervous system by affinity cell-capture mass spectrometry. J Proteome Res 8: 1271-1284.

Zhang K, Osakada Y, Vrljic M, Chen L, Mudrakola HV, Cui B (2010). Single-molecule imaging of NGF axonal transport in microfluidic devices. Lab Chip 10: 2566-2573.

Zhang ZC, Wang JH, Hui LM, Li LJ (2012). Poly(glycidyl methacrylate-divinylbenzene) based immobilized $\mathrm{pH}$ gradient capillary isoelectric focusing coupling with MALDI mass spectrometry for enhanced neuropeptide analysis. Electrophoresis 33: $661-665$

Zhong M, Lee CY, Croushore CA, Sweedler JV (2012). Label-free quantitation of peptide release from neurons in a microfluidic device with mass spectrometry imaging. Lab Chip 12: 2037-2045.

Zhou B, Wang JL, Ressom HW (2012). MetaboSearch: tool for mass-based metabolite identification using multiple databases. PLoS One 7.

Zimmerman TA, Rubakhin SS, Romanova EV, Tucker KR, Sweedler JV (2009). MALDI mass spectrometric imaging using the stretched sample method to reveal neuropeptide distributions in aplysia nervous tissue. Anal Chem 81 : 9402-9409.

Zimmerman TA, Rubakhin SS, Sweedler JV (2011). MALDI mass spectrometry imaging of neuronal cell cultures. J Am Soc Mass Spectrom 22: 828-836. 